\title{
MEMBANGUN GENERASI KRITIS MELALUI KETERAMPILAN LITERASI DIGITAL
}

\author{
Tania Intan ${ }^{1)}$, Vincentia Tri Handayani ${ }^{2)}$, Nurul Hikmayaty Saefullah ${ }^{2)}$ \\ 1)Departemen Sastra dan Kajian Budaya, FIB, Universitas Padjadjaran, Bandung, Jawa Barat, Indonesia \\ ${ }^{2}$ Departemen Linguistik, FIB, Universitas Padjadjaran, Bandung, Jawa Barat, Indonesia \\ Corresponding author : Tania Intan \\ E-mail : tania.intan@unpad.ac.id
}

Diterima 30 Agustus 2021, Direvisi 09 September 2021, Disetujui 09 September 2021

\begin{abstract}
ABSTRAK
Mengamati perkembangan teknologi digital pada masyarakat saat ini, terungkap adanya peningkatan partisipasi aktif masyarakat dalam kegiatan literasi digital termasuk pada pemanfaatan media digital dan internet sebagai akses informasi dan pelayanan publik. Untuk menjadi literat digital yang mampu memproses, memahami, dan menyeleksi berbagai informasi dibutuhkan kecakapan tersendiri. Dalam upaya mencapai kompetensi tersebut, tim pengabdian pada masyarakat dari Universitas Padjadjaran bekerja sama dengan mahasiswa KKN sesi Juli - Agustus 2021 menyelenggarakan sejumlah kegiatan yang bertujuan untuk (1) menginformasikan cara pemanfaatan media sosial sebagai wadah yang berdaya guna dan (2) mengedukasi pembuatan konten yang berkualitas dan tepat sasaran di media sosial. Publik primer yang disasar adalah mereka yang berusia produktif 17-26 tahun, dan publik sekunder yang terdiri dari masyarakat umum pengguna media sosial. Tim PPM mengajak mitra terkait yang memiliki program tanggung jawab sosial perusahaan dan kepedulian terhadap literasi digital, yaitu Telkomsel untuk bersama-sama menciptakan ekosistem digital yang positif di Indonesia. Kegiatan dilaksanakan dengan metode sosialisasi, edukasi, dan diskusi, melalui Kampanye Sosial dan Webinar Cakap Bermedia Digital untuk Pengembangan Potensi Diri. Selain adanya tambahan pengetahuan dan keterampilan pada publik sasaran, indikator keberhasilan yang ditunjukkan oleh kegiatan pengabdian masyarakat ini adalah jumlah peserta kampanye dan webinar yang melebihi target, yaitu mencapai 114 orang.
\end{abstract}

Kata kunci: generasi kritis; media sosial; literasi digital; pengembangan potensi diri.

\begin{abstract}
Observing the development of digital technology in today's society, it was revealed that there was an increase in the active participation of the community in digital literacy activities, including the use of digital media and the internet as access to information and public services. To become a digital literate who can process, understand, and select various information requires its skills. To achieve these competencies, the community service team from Padjadjaran University in collaboration with KKN students for the July - August 2021 session held some activities aimed at (1) informing how to use social media as an efficient forum and (2) educating the creation of quality content. and right on target on social media. The primary public targeted are those in the productive age of 17-26 years, and the secondary public consists of the general public who use social media. The PPM team invites related partners who have corporate social responsibility programs and concern for digital literacy, namely Telkomsel, to jointly create a positive digital ecosystem in Indonesia. Activities are carried out using socialization, education, and discussion methods, through Social Campaigns and Webinar Digital Media for SelfPotential Development. In addition to the additional knowledge and skills of the target public, an indicator of success shown by this community service activity is the number of campaign and webinar participants that exceeded the target, which reached 114 people.
\end{abstract}

Keywords: critical generation; social media; digital literacy; self potential development.

\section{PENDAHULUAN}

Pada era revolusi industri 4.0, generasi sekarang tumbuh dengan akses yang tidak terbatas dalam teknologi digital dan diharapkan menjadi masyarakat literat digital, yang melek dan paham segala hal tentang ruang digital. Menjadi literat digital berarti dapat memproses berbagai informasi, dapat memahami pesan, dan berkomunikasi efektif dengan orang lain dalam berbagai bentuk. Kecakapan inilah yang harus diasah dan diarahkan karena arus penyebaran informasi semakin deras dan kemampuan membuat konten positif dan kreatif terbatas oleh pengetahuan masing-masing pengguna internet. 
Sebagai ilustrasi, sumber-sumber digital dapat dimanfaatkan sebagai sarana pemasaran seperti yang diteliti oleh Liana dkk (2021). Sementara itu, dalam dunia pendidikan, internet merupakan sarana yang sangat kaya dengan informasi dan dapat meningkatkan kualitas kinerja sebagaimana ditunjukkan dalam kajian Syaharuddin dkk (2020). Pemanfaatan positif atas ruang dalam dunia maya juga ditunjukkan oleh Cyber Kartini, yang menurut Anwar (2018: 73) adalah istilah yang ditujukan pada perempuan Indonesia yang menggunakan media sosial untuk hal-hal yang bermanfaat seperti berdagang, menulis, mengajar, menampilkan hasil karya, atau sekedar berbincang untuk berbagi pengalaman. Situasi ini membuktikan bahwa media sosial merupakan sarana untuk menghubungkan manusia dan bertujuan untuk mencapai kualitas kehidupan yang lebih baik, sebagaimana diargumentasikan oleh Turkle (2011: 13).

Selain membawa manfaat yang sangat besar, ternyata internet pun memiliki potensi untuk disalahgunakan. Fenomena ini misalnya ditunjukkan oleh penelitian Majorsy dkk. (2017: 91) yang menemukan bahwa internet dapat menimbulkan kecanduan karena memuat dimensi petualangan, dimensi pelarian diri, dan dimensi cinta. Internet dapat pula dimanfaatkan oleh pihak-pihak yang tidak bertanggung jawab untuk mempraktikkan kekerasan berbasis gender, yang menurut Mauliya (2021: 1), meningkat jumlahnya di masa pandemi Covid19 ini. Bentuk kekerasan berbasis gender online ini misalnya dalam bentuk pencemaran nama baik, penipuan, ujaran kebencian, bullying, dan sebagainya. Selain itu, kurangnya kemampuan pembaca dalam memahami pesan dan misinterpretasi berita dapat menjadi alasan berkembangnya berbagai macam hoaks akhirakhir ini (Widiyanti, 2020: 79). Situasi ini memperlihatkan tantangan dalam era disrupsi. $\mathrm{Di}$ satu pihak, ada bermacam-macam kemudahan dan kesempatan baru, namun di pihak lain, media digital menyimpan ancaman yang membahayakan penggunanya.

$$
\text { Mengamati kenyataan }
$$

permasalahan yang ada dan berkembang dalam masyarakat berkenaan dengan pemanfaatan internet tersebut, tim PPM dengan ketua Vincentia Tri Handayani, S.S., M.Hum. mengangkat tema "Cakap Bermedia Digital untuk Pengembangan Potensi Diri". Tema tersebut dipilih dengan latar belakang pemikiran bahwa keterampilan literasi digital dapat dioptimalkan dengan cara membangun pola pikir kritis dan pemahaman dalam penggunaan teknologi komunikasi secara bijaksana.

\section{Perbincangan tentang literasi} dinyatakan Nugraha (2020) diawali dengan Gerakan Literasi Nasional pada tahun 2015. Kern, melalui Mustika (2021: 210), menyebutkan bahwa literasi berarti "penggunaan praktik-praktik secara sosial, historis, dan budaya untuk menciptakan dan menafsirkan makna melalui teks. Untuk itu dibutuhkan kesadaran tentang hubungan antara konvensi tekstual dengan konteks penggunaannya, dan idealnya ada kemampuan untuk merefleksikan hubungan tersebut secara kritis". Dalam konteks kekinian, literasi kerap dikaitkan dengan teknologi digital.

Melalui Erika (2019: 38), literasi digital didefinisikan Ray sebagai keterampilan yang tepat dalam menggunakan teknologi untuk mencapai tujuan. Keterampilan literasi digital meliputi pengetahuan dan kemampuan seputar atribut teknologi digital yang memungkinkan individu untuk meningkatkan potensi belajar, kehidupan, dan pekerjaan mereka di era digital. Herlina dkk menjelaskan melalui Erika (2019: 39) bahwa kemahiran suatu generasi dalam media digital ditentukan oleh berbagai faktor yaitu terpaan teknologi digital, tingkat pendidikan ibu, dan tingkat ekonomi keluarga. Hobbs (2010) menjelaskan bahwa terdapat lima kompetensi dalam literasi digital. Pertama, kompetensi akses yang berarti individu terampil dalam memanfaatkan platform dalam media digital dan berbagi informasi yang relevan dengan orang lain. Kedua, kompetensi analisis dan evaluasi yang berarti individu memahami pesan dan kritis dalam menilai serta menganalisis kualitas pesan dilihat dari kebenaran, kredibilitas, dan sudut pandang pembuat pesan, serta mampu memahami efek dan konsekuensi yang ditimbulkan oleh pesan. Ketiga, kompetensi produksi yang mencakup kemampuan individu dalam menulis dan menghasilkan konten dengan menggunakan kreativitas dan mampu memproduksinya dengan teknik yang sesuai dengan platform media digital sesuai dengan pesan, audiens, dan tujuannya. Keempat, kompetensi refleksi, produksi, dan distribusi yang berarti individu memiliki pemahaman tentang etika dan budaya yang berlaku serta tanggung jawab secara sosial. Kelima, kompetensi kolaborasi yaitu individu dapat bekerjasama dan berpartisipasi dalam lingkungan keluarga, sosial, dan komunitas untuk berbagai pengetahuan dan memecahkan masalah pada tingkat lokal, regional, nasional, dan internasional.

Kelima kompetensi yang diajukan Hobbs tersebut menjadi penting untuk dimiliki karena literasi digital juga berkelindan dengan cara individu memanfaatkan media sosial yang dimiliki. Media sosial sendiri menurut 
Sholikhatin dkk (2020: 254), merupakan alat yang efektif untuk meningkatkan branding diri, baik secara individu maupun organisasi sehingga daya saing dan popularitas dapat menjadi optimal.

\section{METODE}

Metode yang digunakan dalam kegiatan meliputi tiga tahap, yaitu: persiapan, pelaksanaan, dan evaluasi.

\section{Tahap Persiapan}

Pada awal bulan Juli 2021, tim PPM dan mahasiswa KKN yang membantu melakukan perancangan setiap unsur yang dilibatkan dalam kegiatan PPM, yaitu penanggung jawab dan pelaksana kegiatan, waktu dan tempat kegiatan, publik sasaran, mitra kerja, dan hal-hal teknis lainnya. Tim kemudian memutuskan untuk menetapkan sasaran primer kegiatan PPM ini adalah WNI yang berumur 17-26 tahun, sedangkan sasaran sekunder adalah masyarakat umum yang aktif menggunakan media sosial.

Selanjutnya, tim merencanakan kegiatan-kegiatan secara lebih detil pada akhir bulan Juli 2021. Diputuskan bahwa ada dua fokus pembahasan yang diangkat terkait permasalahan literasi digital, yaitu: (1) Digital Media Strategy: Strategi Pemanfaatan Media Sosial sebagai Wadah Marketing bagi Generasi Milenial, dan (2) Upgrading Your Digital Skills to be a Creator. Penggunaan bahasa Inggris dalam hal ini dilakukan untuk lebih menarik minat dan perhatian kelompok sasaran. Tim melakukan pertemuan daring dengan representasi dari Telkomsel untuk membahas materi dan pelaksanaan kegiatan pada tanggal 2 Agustus 2021. Sepanjang tanggal 4-12 Agustus 2021 dilakukan publikasi kegiatan melalui media sosial tim dan mahasiswa KKN yang membantu.

\section{Tahap Pelaksanaan}

Kampanye Sosial merupakan acara awal atau pre event, yang ditujukan untuk memberikan informasi serta ajakan untuk membangun keterampilan literasi digital yang disajikan melalui platform Instagram Feeds dan Instagram Story pada tanggal 10 Agustus 2021. Sementara itu, sebagai acara utama atau main event, webinar dengan dua pakar komunikasi dan informatika dari Telkomsel direncanakan diselenggarakan pada hari Jumat tanggal 13 Agustus 2021 pukul 12.30 sampai selesai. Para peserta yang telah diundang sebelumnya melalui aplikasi grup Whatsapp telah mengonfirmasi kehadiran mereka, sehingga pada hari kegiatan seluruh peserta hadir pada waktunya.
Webinar bertema "Cakap Bermedia Digital untuk Pengembangan Potensi Diri, kegiatan dilaksanakan secara daring dengan menggunakan media Zoom Meeting. Pembicara pertama, Reinhard Giofan Pardede dari Marketing Lead by.U memaparkan materi "Digital Media Strategy: Strategi Pemanfaatan Media Sosial sebagai Wadah Marketing bagi Generasi Milenial". Pembicara berikutnya, Aji Achmad Ahimsa merupakan Own Digital Creative Telkomsel yang membawakan materi "Upgrading Your Digital Skills to Be A Creator".

Perusahaan di bidang provider, termasuk Telkomsel, dianggap memiliki peran penting untuk bersama-sama dengan perguruan tinggi dalam membangun kepedulian terhadap literasi digital. Mereka juga memiliki program tanggung jawab sosial perusahaan (Corporate Social Responsibility CSR). Program tersebut pada umumnya merupakan pendekatan bisnis dengan memberikan kontribusi terhadap pembangunan berkelanjutan.

\section{Tahap Evaluasi}

Tahap terakhir ini merupakan waktu bagi tim PPM untuk mengevaluasi kegiatan yang telah dilakukan dan juga mengukur keberhasilan sekaligus kekurangan. Catatan hasil evaluasi terhadap kegiatan ini dijadikan tolok ukur untuk penyelenggaraan kegiatan sejenis atau yang relevan pada kesempatan lain. Hasil penilaian ini pun digunakan untuk mempertimbangkan rencana kegiatan lain.

\section{HASIL DAN PEMBAHASAN}

Seluruh kegiatan PPM dilakukan secara daring mengingat situasi pandemi Covid-19 yang masih terjadi. Dalam keterbatasan tersebut, dapat dinyatakan bahwa seluruh kegiatan PPM berjalan dengan lancar dan sukses. Pertemuan dalam ruang virtual juga dianggap menguntungkan karena selain lebih murah, juga dapat menjangkau lebih banyak peserta karena tidak dibatasi oleh ruang dan waktu.

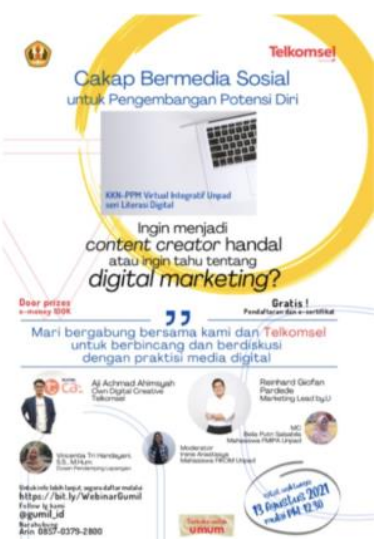

Gambar 1. Poster Webinar Literasi Digital 
Melalui akun gumil_id, tim PPM

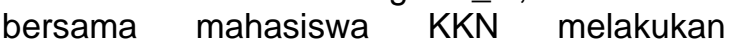
sosialisasi informasi mengenai digital skills dan publikasi tentang acara pre-event maupun main event berupa webinar.

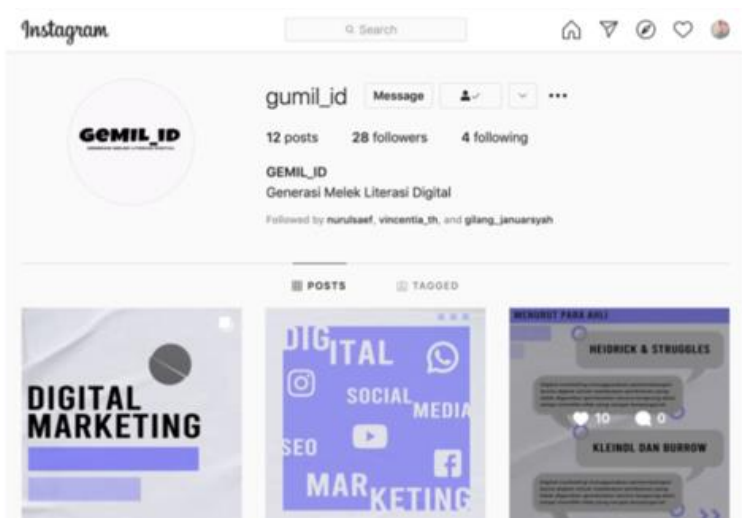

Gambar 2. Tangkap Layar Publikasi Kegiatan pada Platform Instagram

Pada acara tanya jawab yang diselenggarakan oleh Gumil (Generasi Melek Literasi Digital) bekerja sama dengan Telkomsel pada tanggal 11 Agustus 2021, disampaikan latar belakang pemilihan tema kegiatan, yaitu karena ditemukan ketimpangan di antara kemajuan teknologi dengan kemampuan masyarakat dalam memanfaatkannya. Deasy Apriani, selaku Manager Corporate Reputation Telkomsel, menyampaikan bahwa literasi digital harus dibangun mulai dari unit komunitas sosial terkecil yaitu keluarga. Telkomsel sendiri telah mendukung berkembangnya literasi digital di Indonesia melalui penyediaan jaringan, wadah komunikasi, dan ilmu.

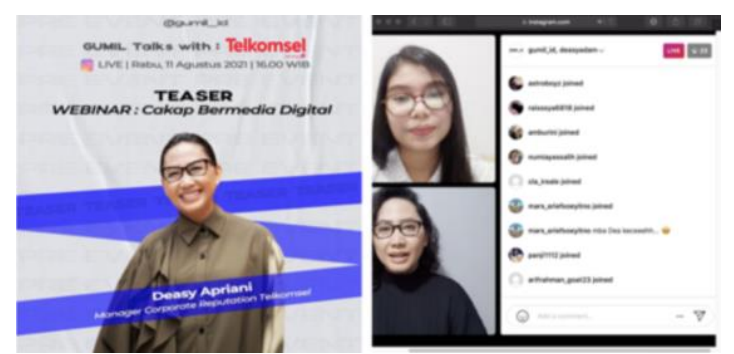

Gambar 3. Poster dan Diskusi pada IG Live

Sementara itu, webinar yang diselenggarakan pada tanggal 13 Agustus 2021 mulai pukul 12.30 sampai dengan pukul 16.00. Webinar dibuka dengan sambutan dari ketua panitia mahasiswa KKN, ketua tim PPM sekaligus DPL, Manajer Riset, Kerjasama, dan Inovasi FIB, serta VP Corporate Communications Telkomsel. Pada awal webinar, pembicara pertama menjelaskan arti content creator, yaitu orang-orang yang membuat konten di dalam media online untuk menarik perhatian dan minat masyarakat umum atau konsumen yang khusus. Mereka berperan serta dalam menargetkan audiens dan beroperasi dalam ruang digital termasuk media sosial. Karya content creator dapat berupa video, foto, desain, script, lagu, dan sebagainya. Tujuan pembuatan konten beragam, mulai dari untuk edukasi, hiburan, bisnis, dan yang lainnya. Mereka biasanya memanfaatkan berbagai platform digital, terutama media sosial seperti Youtube, Tiktok, Instagram, Facebook, Podcast, dan lain-lain.

Saat ini content creator merupakan profesi yang menjanjikan, karena mereka yang 'berhasil' seperti Atta Halilintar, Deddy Corbuzier, Raditya Dika, dan Tasya Farasya mendapatkan penghasilan yang besar. Mereka membangun popularitas melalui iklan, endorse produk, hingga bekerja sama dengan brand kenamaan. Untuk membangun suasana menjadi lebih hangat, pembicara menghadirkan content creator peringkat 2 di Indonesia yaitu Vito Sinaga, sebagai partner dalam sesi tersebut.

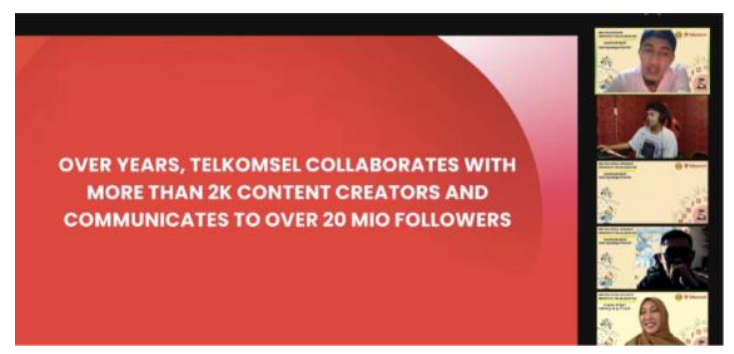

Gambar 4. Lembar Tayangan Webinar Sesi1

Pada sesi berikutnya, sejumlah materi disampaikan. Salah satu di antaranya adalah penjelasan mengenai keunggulan dari digital marketing, yaitu (1) kecepatan penyebaran, (2) kemudahan evaluasi, (3) jangkauan lebih luas, (4) murah dan efektif, dan (5) membangun nama brand. Digital marketing menggunakan perkembangan dunia digital untuk melakukan periklanan yang tidak digembar-gemborkan secara langsung akan tetapi memiliki efek yang sangat berpengaruh.

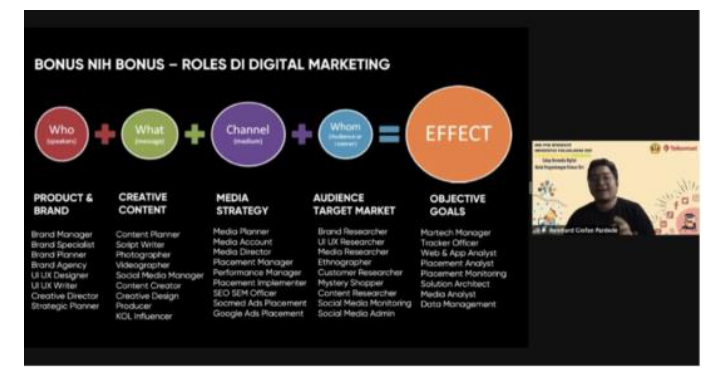

Gambar 5. Lembar Tayangan Webinar Sesi 2 
Selain pembahasan penggunaan dunia digital untuk keperluan perdagangan dalam start up dalam konteks usaha kecil dan menengah, pembicara kedua juga menyajikan berbagai strategi untuk memasarkan produk. Secara keseluruhan, pelaksanaan kegiatan PPM dapat dinilai terselenggara dengan lancar dan sukses, sebagaimana ditunjukkan oleh partisipasi dari sekitar 114 peserta yang hadir. Pada akhir setiap sesi diadakan tanya jawab yang sangat aktif dan berkualitas. Tim PPM dan Telkomsel sebagai partner menyediakan hadiah untuk para penanya dan pemenang quizziz. Sebagai bentuk evaluasi, disediakan link kuesioner. Seluruh peserta menyatakan kepuasan atas penyelenggaraan kegiatan ini, karena mendapatkan ilmu yang bermanfaat dari para pakar telekomunikasi dan komunikasi, e-certificate, doorprize, dan tidak berbayar.

\section{SIMPULAN DAN SARAN}

Penerapan literasi digital, sebagaimana disebutkan Putri (2021), dapat membuat masyarakat menjadi jauh lebih bijak dalam menggunakan dan mengakses teknologi. Gagasan tersebutlah yang menjadi dasar pemikiran dari pelaksanaan kegiatan PPM dengan tujuan Membangun Generasi Kritis melalui Keterampilan Literasi Digital. Secara keseluruhan, kegiatan telah dilaksanakan dengan baik dan tuntas. Tim menyarankan agar kerjasama dengan berbagai institusi, seperti Telkomsel, terus dibangun karena keterlibatan mereka memiliki peran penting untuk mendukung penyebaran keterampilan literasi digital. Tim mengharap ada manfaat ekonomi, sosial, dan lingkungan dari kegiatan yang telah dilaksanakan bagi seluruh pemangku kepentingan.

\section{UCAPAN TERIMAKASIH}

Tim PPM menyampaikan ucapan terima kasih kepada Rektor Universitas Padjadjaran, Direktur Riset, Pengabdian, dan Inovasi Unpad, Dekan FIB, dan Bapak Deni Abidin selaku VP Corporate Communications Telkomsel yang telah memfasilitasi kegiatan pengabdian kepada masyarakat ini sehingga setiap tahap kegiatan dapat terselenggara dengan baik. Tim juga berterima kasih pada para mahasiswa peserta KKN sesi Juli-Agustus 2021, dan semua pihak yang membantu kegiatan ini.

\section{DAFTAR RUJUKAN}

Anwar, C. R. (2018). Cyber Kartini: Aktivitas Pendidik Perempuan di Media Sosial. Etnosia: Jurnal Etnografi Indonesia, 3(1), 72-93.
Erika, D. (2019). Literasi Digital Perempuan pada Organisasi Persatuan Istri Prajurit (Persit). Interaksi: Jurnal IImu Komunikasi, 8(2), 36-45.

Hobbs, R. (2010). Digital and media literacy a plan of action: White paper. Washington D.C: The Aspen Institute.

Liana, A., Sulfaidah, Maisya Zahra Al Banna. (2021). Klinik Pemasaran Digital bagi Dosen Berwirausaha. Selaparang: Jurnal Pengabdian Masyarakat Berkemajuan, 4(2), 443-450.

Majorsy, U., Indria Hapsari, Vega Valentine, Aprilia Maharani Ayuningsih. (2017). Contribution of Cyber-relationship Motive to Internet Addiction in Adults. Analitika, 9(2), 91-96.

Mauliya, A., Triana Rosalina Noor. (2021). Cyber Safety dalam Merespon Kekerasan Berbasis Gender Online di Masa Pandemi Covid-19. Jurnal Khitah: Kajian Islam, Budaya \& Humaniora, 2(1), 1-13.

Mustika, S., Tellys Corliana, Andys Tiara. (2021). Pelatihan Literasi Media tentang Kesetaraan Gender bagi Siswa SMA Muhammadiyah 3 Jakarta Selatan. Jurnal Solma, 10(1), 207-215.

Nugraha, D., Dian Octavianah. (2020). Diskursus Literasi Abad 21 di Indonesia. Jurnal Pendidikan Edutama, 7(1), 107126.

Putri, V. K. M. (2021). Literasi Digital: Pengertian, Prinsip, Manfaat, Tantangan dan Contoh. Kompas.com. https://www.kompas.com/skola/read/20 21/06/15/142539669/literasi-digitalpengertian-prinsip-manfaat-tantangandan-contoh

Sholikhatin, S. A., Wanda Fitrianingsih, Sahira Dhiyaulhaq. (2020). Workshop Strategi Peningkatan Popularitas Konten serta Menjaga Keamanan Data Pribadi di Berbagai Platform Media Sosial. Selaparang: Jurnal Pengabdian Masyarakat Berkemajuan, 4(1), 251255.

Syaharuddin, H. R. P. N., Malik Ibrahim, Vera Mandailina, Dewi Pramita, Farah Heniati Santosa. (2020). Penelusuran Referensi Berbasis Digital sebagai Peningkatan Soft Skill Mahasiswa dalam Menyelesaikan Tugas Akhir. Selaparang: Jurnal Pengabdian Masyarakat Berkemajuan, 3(2), 151155.

Turkle, S. (2011). Alone together: why we expect more than technology and less from each other. New York: Basic Books. 
Widiyanti, I. (2020). Informasi Berita Hoaks dari Perspektif Bahasa. BASINDO : Jurnal Kajian Bahasa, Sastra Indonesia, dan Pembelajarannya, 4(1), 78-86. 